\title{
Carvão ativado no estabelecimento in vitro de cultivares de framboeseira
}

\author{
Activated charcoal in the in vitro establishment of raspberry cultivars
}

\section{Cíntia de Moraes Fagundes, Roseane Maidana Moreira, Aline Ramm, Márcia Wulff Schuch e Zeni Fonseca Pinto Tomaz*}

Submissão: 23/01/2017 / Aceite: 02/05/2017

\section{RESUMO}

A propagação da framboeseira (Rubus idaeus L.) é comumente realizada a partir da estacas de raízes. Embora, os frutos possuam sementes viáveis, a reprodução sexuada não é desejada, em razão, de algumas desvantagens, tais como: dormência, elevada variabilidade genética período de juvenilidade. Dessa forma, a micropropagação in vitro é uma técnica viável para o processo de formação de mudas, pois, preserva características genéticas desejáveis das plantas-matrizes, servindo como uma alternativa para os produtores. Objetivou-se então avaliar o efeito de diferentes concentrações de carvão ativado, suplementado ao meio de cultura para as diferentes cultivares de framboeseira. Utilizaram-se o carvão

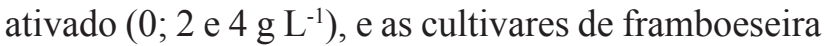
(Indian Summer, Heritage, Willamette, Golden Bliss, Polana, Fallgold, Schönemann e Bababerry). O delineamento experimental utilizado foi inteiramente casualizado arranjado em esquema bifatorial, com quatro repetições. Cada repetição composta por 25 tubos e um explante por tubo. Melhor controle de oxidação foi observado para as cultivares Golden Bliss, Polana, Fallgold, Schönemann e Bababerry, cultivados em meio de cultura acrescido de $4 \mathrm{~g} \mathrm{~L}^{-1}$ de carvão ativado, devido a absorção de compostos fenólicos liberados no meio de cultura.

PALAVRAS-CHAVE: Rubus idaeus, oxidação, micropropagação, antioxidante, compostos fenólicos.

\section{ABSTRACT}

Propagation of raspberry (Rubus idaeus L.) is usually performed from root cuttings. Although fruits have viable seeds, sexual reproduction is unwanted due to the high genetic variability and long juvenile period besides dormancy, which causes plant development to be slow and consequently produces the same result in the production of new seedlings. So, in vitro micropropagation is a viable technique for seedling production, thus maintaining genetic features of the mother plant, uniformity, precocity of production, as well as accelerating the conventional propagation methods, are an alternative to planters. The aim was the evaluation of the effect of different concentration ratios of activated charcoal supplied in the growth medium on the different raspberry cultivars. Activated charcoal was used $\left(0 ; 2\right.$; and $\left.4 \mathrm{~g} \mathrm{~L}^{-1}\right)$, and the raspberry cultivars were (Indian Summer, Heritage, Willamette, Golden Bliss, Polana, Fallgold, Schönemann, and Bababerry). The best oxidation control was presented on cultivars Golden Bliss, Polana, Fallgold, Schönemann, and Bababerry, grown on cultivation medium added of $4 \mathrm{~g} \mathrm{~L}^{-1}$ activated charcoal, due to the absorption of phenolic compounds released into the culture medium.

KEYWORDS: Rubus idaeus, oxidation, micropropagation, antioxidant, phenolic compounds.

\section{INTRODUÇÃO}

No contexto da produção de frutas de clima temperado, as pequenas frutas ainda são pouco expressivas, porém, estão em constante avanço (FACHINELLO et al. 2011). O aumento do cultivo é reflexo, principalmente, do aumento da demanda destas espécies, tanto nacional quanto internacional. As framboesas (Rubus idaeus L.) destacam-se por sua coloração, sabor e aroma (ANTONIOLLI 2011) além de serem ricas em nutrientes tais como antocianinas, aminoácidos e vitaminas (HAN et al. 2004).

Universidade Federal de Pelotas, Pelotas, RS, Brasil.

*Autor para correspondência<zfptomaz@yahoo.com.br> 
No Brasil, o cultivo ainda é incipiente. Contudo, tem apresentado um crescimento considerável em área plantada nos últimos anos. Em 2004, assumia-se que a framboeseira ocupava 40 hectares (RASEIRA et al. 2004). Estima-se, que em 2011 esta área tenha duplicado ou triplicado, constituindo 100 a 150 hectares cultivados, distribuídos nos Estados do Rio Grande do Sul, Santa Catarina, Minas Gerais e São Paulo (GONÇALVES et al. 2011).

O sul do Brasil tem grande potencial para a produção de pequenas frutas. Devido à intensa manutenção do pomar e, principalmente, à reduzida utilização de agrotóxicos, apresentando-se assim como opção para a agricultura familiar. São culturas de retorno rápido, pois no segundo ano entram em produção, proporcionando ao agricultor familiar opções de renda (ANTUNES 2006).

Apesar de se conhecer as possibilidades de exploração dessa espécie, há escassez de estudos no Brasil. Os investimentos em pesquisas para definir práticas culturais nestas espécies ainda são poucos para a definição de um sistema de produção.

O conhecimento de métodos de propagação e formação de mudas pode ser o primeiro passo para expansão da cultura no Brasil, sendo essa uma linha de pesquisa importante para ser seguida (AFFONSO et al. 2015).

Embora os frutos da framboeseira possuam sementes viáveis, a reprodução sexuada não é desejada no estabelecimento de plantios comerciais, em razão da elevada variabilidade genética e do longo período juvenil, além da dormência (TEZOTTO-ULIANA \& KLUGE 2013). Sendo assim, a micropropagação é uma técnica viável para o processo de formação de mudas, mantendo, assim, as características genéticas das plantas-matrizes, uniformidade, precocidade de produção e acelerando os métodos de propagação convencional sendo uma alternativa para os produtores (JUNGHANS \& SOUZA 2013).

$\mathrm{O}$ estabelecimento in vitro dos explantes corresponde à primeira etapa do sistema de micropropagação, iniciando-se com a seleção dos explantes mais adequados para a subsequente multiplicação e terminando com a obtenção de uma cultura suficientemente adaptada às condições in vitro (GRATTAPAGLIA \& MACHADO 1998). No entanto, um problema da propagação por esta técnica é a oxidação dos explantes de framboeseira in vitro, devido aos compostos fenólicos da planta.

Por se tratar de uma espécie semilenhosa, ao ser cultivada in vitro, a framboeseira libera exsudatos derivados da oxidação de compostos fenólicos, sendo necessário o uso de antioxidantes no meio de cultura. A oxidação ocorre em função da liberação de compostos fenólicos in vitro, precursores da síntese de lignina, pelo tecido injuriado. Esse acúmulo de polifenóis e produtos de oxidação, como melanina, suberina, lignina, cutina e calose em torno da superfície excisada, modificam a composição do meio de cultivo e a absorção de metabólitos (ANDRADE et al. 2000).

GRATTAPAGLIA \& MACHADO (1998) recomendam para controlar a oxidação as seguintes medidas: lavagem do material antes da desinfestação em água corrente, auxiliando na lixiviação dos compostos fenólicos; utilização de antioxidantes: ácido ascórbico, polivinilpirrolidone (PVP), carvão ativado e incubação inicial dos explantes no escuro. A atividade das enzimas no que diz respeito à biossíntese e oxidação de fenóis é aumentada pela luz, portanto, o escurecimento dos tecidos poderá ser reduzido e até mesmo impedido, caso os explantes sejam cultivados no escuro.

Sendo assim, pode-se salientar que o carvão ativado, além de atuar como potencial antioxidante, promove a adsorção de hormônios (auxinas e citocininas), exsudatos das plantas e metabólicos tóxicos. Além disso, esse aditivo pode exercer importante função no controle da liberação dos metabólicos, propiciando um ambiente onde os explantes não ficam expostos a luz, quando recém inoculados.

Diante da necessidade de se desenvolver protocolos que, solucionem um problema recorrente no estabelecimento in vitro da espécie, o presente trabalho teve por objetivo avaliar o efeito de diferentes concentrações de carvão ativado, adicionados ao meio de cultura para as diferentes cultivares de framboeseira.

\section{MATERIAL E MÉTODOS}

O experimento foi conduzido no Laboratório de Propagação de Plantas Frutíferas, no Departamento de Fitotecnia da Faculdade de Agronomia Eliseu Maciel (FAEM), da Universidade Federal de Pelotas (UFPel), Capão do Leão, RS, no período de 2013-2014.

Para o estabelecimento in vitro da framboeseira foram utilizadas plantas matrizes, que estavam no período de crescimento vegetativo, com dois anos de 
idade pertencentes ao Banco Ativo de Germoplasma da UFPel mantidas em vasos de nove litros e cultivadas em substrato Plantmax ${ }^{\circledR}$. As plantas foram irrigadas diariamente, intercalando a irrigação com água e solução nutritiva (SCHUCH \& PEIL 2012), a cada 15 dias, visando atender as necessidades hídricas e nutricionais da cultura. Para diminuir a contaminação in vitro, as plantas matrizes foram pulverizadas a cada dois dias, durante todo o ano, com bactericida $\left(\right.$ Kasumin $\left.^{\circledR}\right)$ e fungicida $\left(\right.$ Cercobin $\left.^{\circledR}\right)$ nas doses de 3 $\mathrm{mL} \mathrm{L}^{-1}$ e $0,7 \mathrm{~g} \mathrm{~L}^{-1}$, respectivamente.

$\mathrm{O}$ delineamento experimental utilizado foi inteiramente casualizado arranjado em esquema bifatorial, com quatro repetições. Cada repetição foi composta por 25 tubos e um explante por tubo. $\mathrm{O}$ fator de tratamento A testou as cultivares (Indian Summer, Heritage, Willamette, Golden Bliss, Polana, Fallgold, Schönemann e Bababerry) e, o fator B as doses de carvão ativado $\left(0 ; 2\right.$ e $\left.4 \mathrm{~g} \mathrm{~L}^{-1}\right)$.

Os explantes de framboeseira foram coletados no verão, com aproximadamente dois centímetros e com duas gemas. Essas brotações tiveram suas folhas removidas na coleta. Primeiramente, os explantes foram desinfestados utilizando álcool $70 \%$ sob agitação durante um minuto e, posteriormente imersos em hipoclorito de sódio ( $2,5 \%$ de cloro ativo) com adição de duas gotas de Tween $20^{\circledR}$ e novamente submetidos a agitação (15 minutos). Na sequência, o material desinfestado foi lavado três vezes com água destilada autoclavada e esterilizada em câmara de fluxo laminar, para posterior isolamento dos explantes.

$\mathrm{O}$ meio de cultura onde foram inoculados os explantes foi constituído pelos sais e vitaminas do meio MS (MURASHIGE \& SKOOG 1962), acrescido de diferentes doses de carvão ativado $\left(0 ; 2\right.$ e $\left.4 \mathrm{~g} \mathrm{~L}^{-1}\right)$, $100 \mathrm{mg} \mathrm{L}^{-1}$ de mio-inositol, $30 \mathrm{~g} \mathrm{~L}^{-1}$ de sacarose, sendo o pH ajustado para 5,8 antes da inclusão do ágar $\left(7 \mathrm{~g} \mathrm{~L}^{-1}\right)$. Na sequência, os tubos de ensaio ( $150 \times 20$ $\mathrm{mm}$ ) contendo $7 \mathrm{~mL}$ de meio de cultura, foram vedados com tampas de papel alumínio e autoclavados $\left(121^{\circ} \mathrm{C}\right.$ e 1,5 atm) por 20 minutos.

Após a inoculação, os explantes foram mantidos no escuro, dentro de caixas de papelão com as tampas vedadas, por um período de sete dias, sendo este um procedimento padrão para diminuir a oxidação fenólica. Em seguida, foram transferidos para sala de crescimento com fotoperíodo de 16 horas de luz, com radiação de $27 \mu \mathrm{mol} \mathrm{m} \mathrm{m}^{-2} \mathrm{~s}^{-1}$, temperatura de $25 \pm 2{ }^{\circ} \mathrm{C}$ e umidade de $50 \%$.

Aos 28 dias após a inoculação foi avaliado a percentagem de contaminação fúngica, bacteriana e de explantes oxidados. Aos 45 dias avaliouse a percentagem de sobrevivência, indicada pela coloração verde dos segmentos nodais, e a percentagem de estabelecimento, que foi determinada pelo desenvolvimento de primórdios foliares e presença de brotações.

Os dados foram analisados quanto à normalidade pelo teste de Shapiro-Wilk; à homocedasticidade pelo teste de Hartley; e, a independência dos resíduos por análise gráfica. Posteriormente, os dados foram submetidos à análise de variância através do teste $\mathrm{F}$ $(p \leq 0,05)$. Constatando-se significância estatística, os efeitos das cultivares foram comparados pelo teste de Duncan $(p \leq 0,05)$ e doses por modelos de regressão $(\mathrm{p} \leq 0,05)$, conforme segue:

$$
y=y_{o}+a x ; y=y_{o}+a x+b x^{2}
$$

onde: $\mathrm{y}=$ variável resposta; $\mathrm{y}_{\mathrm{o}}=$ variável resposta correspondente ao ponto mínimo da curva; $\mathrm{a}=$ valor máximo estimado para a variável resposta; $b$ $=$ declividade da curva; $\mathrm{x}=$ dose de carvão ativado $\left(\mathrm{g} \mathrm{L}^{-1}\right)$. A presença de correlações entre as variáveis dependentes do estudo foi analisada através do coeficiente de correlação de Pearson de forma geral para todo o experimento e também, de forma separada para cada cultivar.

\section{RESULTADOS E DISCUSSÃO}

Com exceção a variável porcentagem de estabelecimento in vitro, para as demais variáveis dependentes analisadas ocorreu interação entre os fatores cultivar e dose (Tabelas 1 e 2).

Quanto a variável oxidação fenólica, verificouse que no controle $\left(0 \mathrm{~g} \mathrm{~L}^{-1}\right)$, as cultivares Indian Summer, Golden Bliss, Fallgold e Bababerry demonstraram o mesmo comportamento, com maiores percentuais de oxidação. Na dose de $2 \mathrm{~g} \mathrm{~L}^{-1}$ de carvão ativado a cultivar Fallgold se destacou das demais, com o maior percentual de oxidação. Já para dose de $4 \mathrm{~g} \mathrm{~L}^{-1}$ de carvão ativado, as cultivares Schönemann e Bababerry obtiveram os menores percentuais e diferiram de Indian Summer, Heritage, Willamette e Fallgold (Tabela 1).

Os dados de oxidação ajustaram-se ao modelo de regressão polinomial quadrático para todas as cultivares (Indian Summer: F = 292,7592 e p<0,0001; Heritage: $F=27,9305$ e $p<0,0001$; Willamette: 
Tabela 1. Percentual de oxidação, sobrevivência e estabelecimento de explantes de diferentes cultivares de framboeseira em função de doses de carvão ativado. UFPel, Pelotas, RS, 2013/14.

Table 1. Percentage of oxidation, survival and establishment of explants of different raspberry cultivars as a function of activated carbon doses. UFPel, Pelotas, RS, 2013/14.

\begin{tabular}{|c|c|c|c|}
\hline \multirow{3}{*}{ Cultivar } & \multicolumn{3}{|c|}{ Dose de carvão ativado $\left(\mathrm{g} \mathrm{L}^{-1}\right)$} \\
\hline & 0 & 2 & 4 \\
\hline & \multicolumn{3}{|c|}{ Oxidação (\%) } \\
\hline Indian Summer & $86,00 \mathrm{a}^{\underline{1} /}$ & $11,00 \mathrm{c}$ & $27,50 \mathrm{a}$ \\
\hline Heritage & $60,00 \mathrm{bc}$ & $16,00 \mathrm{c}$ & $21,00 \mathrm{ab}$ \\
\hline Willamette & $50,00 \mathrm{~cd}$ & $12,00 \mathrm{c}$ & $30,00 \mathrm{a}$ \\
\hline Golden Bliss & $73,00 \mathrm{ab}$ & $29,00 \mathrm{~b}$ & $11,00 \mathrm{bcd}$ \\
\hline Polana & $36,00 \mathrm{~d}$ & $19,00 \mathrm{bc}$ & $11,00 \mathrm{bcd}$ \\
\hline Fallgold & $91,00 \mathrm{a}$ & $63,00 \mathrm{a}$ & $20,00 \mathrm{abc}$ \\
\hline Schönemann & $33,00 \mathrm{~d}$ & $9,00 \mathrm{c}$ & $6,00 \mathrm{~d}$ \\
\hline \multirow[t]{2}{*}{ Bababerry } & $77,00 \mathrm{ab}$ & $12,00 \mathrm{c}$ & $9,00 \mathrm{~cd}$ \\
\hline & \multicolumn{3}{|c|}{ Sobrevivência (\%) } \\
\hline Indian Summer & $8,00 \mathrm{c}$ & $84,00 \mathrm{a}$ & $64,50 \mathrm{~b}$ \\
\hline Heritage & $18,00 \mathrm{c}$ & $77,00 \mathrm{a}$ & $71,00 \mathrm{ab}$ \\
\hline Willamette & $35,00 \mathrm{~b}$ & $85,00 \mathrm{a}$ & $63,00 \mathrm{~b}$ \\
\hline Golden Bliss & $13,00 \mathrm{c}$ & $61,00 \mathrm{~b}$ & $84,00 \mathrm{a}$ \\
\hline Polana & $55,00 \mathrm{a}$ & $73,00 \mathrm{a}$ & $85,00 \mathrm{a}$ \\
\hline Fallgold & $4,00 \mathrm{c}$ & $21,00 \mathrm{c}$ & $73,00 \mathrm{ab}$ \\
\hline Schönemann & $58,50 \mathrm{a}$ & $84,00 \mathrm{a}$ & $86,00 \mathrm{a}$ \\
\hline \multirow[t]{2}{*}{ Bababerry } & $4,00 \mathrm{c}$ & $81,00 \mathrm{a}$ & $84,00 \mathrm{a}$ \\
\hline & \multicolumn{3}{|c|}{ Estabelecimento (\%) NS } \\
\hline Indian Summer & 2,00 & 1,00 & 6,00 \\
\hline Heritage & 4,00 & 5,00 & 4,00 \\
\hline Willamette & 4,00 & 1,00 & 5,00 \\
\hline Golden Bliss & 3,00 & 5,00 & 2,00 \\
\hline Polana & 4,00 & 5,00 & 2,00 \\
\hline Fallgold & 1,00 & 5,00 & 3,00 \\
\hline Schönemann & 3,00 & 3,00 & 5,00 \\
\hline Bababerry & 4,00 & 3,00 & 5,00 \\
\hline
\end{tabular}

${ }^{1 /}$ Médias (de quatro repetições \pm erro padrão) acompanhadas por mesma letra minúscula na coluna não diferem entre si pelo teste de Duncan $(\mathrm{p} \leq 0,05)$ comparando as cultivares para cada dose. ${ }^{\text {NS }}$ não significativo pelo teste $\mathrm{F}(\mathrm{p} \leq 0,05)$.

$\mathrm{F}=11,2917$ e $\mathrm{p}=0,0035$; Golden Bliss: $\mathrm{F}=28,5234$ e $\mathrm{p}=0,0001$; Polana: $\mathrm{F}=7,1214$ e $\mathrm{p}=0,0140$; Schönemann: $F=33,9828$ e p < 0,0001; e, Bababerry: $F$ $=30,9000$ e $\mathrm{p}<0,0001$ ), exceto para Fallgold, que teve comportamento linear $(F=107,0276$ e $p<0,0001)$. Para as cultivares Indian Summer, Heritage e Willamette ocorreram acréscimos nos percentuais de oxidação da dose 2 para $4 \mathrm{~g} \mathrm{~L}^{-1}$ de carvão ativado e isso representou 150,1; 309,1 e 150\%, respectivamente (Figura 1A). Para as demais cultivares, ao comparar a dose 2 com 4 $\mathrm{g} \mathrm{L}^{-1}$ de carvão ativado foram verificados decréscimos que variaram de $25 \%$ para cultivar Bababerry a $62,1 \%$ na 'Golden Bliss'.

PAIVA et al. (2007), ao avaliar o efeito da adição de antioxidantes ao meio de cultura para Estrelícia (Strelitzia reginae Ait.), também observou uma tendência de diminuição da ocorrência de oxidação à medida em que foram suplementadas concentrações de carvão ativado ao meio de cultura, entretanto, ao final do estudo concluíram que a dose mais eficiente para controle da oxidação foi $2 \mathrm{~g} \mathrm{~L}^{-1}$. Este resultado diferiu em parte, do resultado encontrado para a cultura da 
Tabela 2. Percentual de contaminação fúngica e bacteriana de explantes de diferentes cultivares de framboeseira em função de doses de carvão ativado. UFPel, Pelotas, RS, 2013/14.

Table 2. Percentage of fungal contamination and explant bacterial different cultivars of raspberry on the function of activated carbon doses. UFPel, Pelotas, RS, 2013/14.

\begin{tabular}{lccc}
\hline \multirow{2}{*}{ Cultivar } & \multicolumn{3}{c}{ Dose de carvão ativado $\left(\mathrm{g} \mathrm{L}^{-1}\right)$} \\
\cline { 2 - 4 } & 0 & 2 & 4 \\
\cline { 2 - 4 } Indian Summer & $4,00 \mathrm{~b}^{1 /}$ & Contaminação fúngica (\%) \\
Heritage & $14,00 \mathrm{a}$ & $2,00 \mathrm{a}$ & $0,00 \mathrm{a}$ \\
Willamette & $4,00 \mathrm{~b}$ & $0,00 \mathrm{a}$ & $3,00 \mathrm{a}$ \\
Golden Bliss & $5,33 \mathrm{~b}$ & $2,00 \mathrm{a}$ & $0,00 \mathrm{a}$ \\
Polana & $4,00 \mathrm{~b}$ & $0,00 \mathrm{a}$ & $4,00 \mathrm{a}$ \\
Fallgold & $4,00 \mathrm{~b}$ & $2,00 \mathrm{a}$ & $2,00 \mathrm{a}$ \\
Schönemann & $4,00 \mathrm{~b}$ & $2,67 \mathrm{a}$ & $3,00 \mathrm{a}$ \\
Bababerry & $4,00 \mathrm{~b}$ & $3,00 \mathrm{a}$ & $3,00 \mathrm{a}$ \\
\hline & & $0,00 \mathrm{a}$ & $2,00 \mathrm{a}$ \\
\hline Indian Summer & $0,00 \mathrm{~d}$ & $2,67 \mathrm{ab}$ & $4,00 \mathrm{a}$ \\
Heritage & $4,00 \mathrm{bcd}$ & $2,00 \mathrm{ab}$ & $1,00 \mathrm{~b}$ \\
Willamette & $5,33 \mathrm{abc}$ & $0,00 \mathrm{~b}$ & $2,00 \mathrm{~b}$ \\
Golden Bliss & $9,33 \mathrm{a}$ & $1,00 \mathrm{~b}$ & $0,00 \mathrm{~b}$ \\
Polana & $2,00 \mathrm{bcd}$ & $1,00 \mathrm{~b}$ & $0,00 \mathrm{~b}$ \\
Fallgold & $0,00 \mathrm{~d}$ & $6,00 \mathrm{a}$ & $0,00 \mathrm{~b}$ \\
Schönemann & $1,00 \mathrm{~cd}$ & $1,00 \mathrm{~b}$ & $0,00 \mathrm{~b}$ \\
Bababerry & $6,67 \mathrm{ab}$ & $3,00 \mathrm{ab}$ & $0,00 \mathrm{~b}$ \\
\hline${ }^{1 / M e ́ d i a s ~(d e ~ q u a t r o ~ r e p e t i c ̧ o ̃ e s ~} \pm$ erro padrão) acompanhadas por mesma letra minúscula na coluna não \\
diferem entre si pelo teste de Duncan $(\mathrm{p} \leq 0,05)$ comparando as cultivares para cada dose.
\end{tabular}

framboeseira, onde a maioria das cultivares, obteve resultados mais eficientes com a adição da maior dose $\left(4 \mathrm{~g} \mathrm{~L}^{-1}\right)$.

O carvão ativado apresenta cargas residuais, as quais são capazes de adsorver substâncias fenólicas ou seus produtos da oxidação, as quinonas, evitando com isso o desencadeamento do processo oxidativo in vitro (THOMAS 2008). Entretanto, o aumento da concentração de carvão ativado pode ser prejudicial ao meio de cultura, pois GALDIANO-JÚNIOR et al. (2010), mencionam que o uso de carvão ativado pode adsorver outras substâncias do meio nutritivo como, por exemplo, os reguladores de crescimento, acarretando efeitos indesejáveis ao cultivo in vitro. Essa circunstância, pode servir como justificativa ao aumento da taxa de oxidação de explantes nas cultivares Indian Summer, Heritage e Willamette, à medida que as doses de carvão ativado suplementadas ao meio de cultura aumentaram.

Para a variável sobrevivência houve comportamento inverso a oxidação. Observou- se que no controle $\left(0 \mathrm{~g} \mathrm{~L}^{-1}\right)$ as cultivares Polana e Schönemann apresentaram o mesmo comportamento, com maiores percentuais de sobrevivência. Na dose de $2 \mathrm{~g} \mathrm{~L}^{-1}$ de carvão ativado as cultivares Fallgold e Golden Bliss se diferenciaram das demais, com os menores percentuais de sobrevivência. Enquanto que na dose de $4 \mathrm{~g} \mathrm{~L}^{-1}$ de carvão ativado, as cultivares Indian Summer e Willamette obtiveram os menores percentuais e diferiram de Golden Bliss, Polana, Schönemann e Bababerry (Tabela 1).

Os dados de sobrevivência ajustaram-se adequadamente ao modelo de regressão polinomial quadrático para todas as cultivares (Indian Summer: $\mathrm{F}=139,1836$ e $\mathrm{p}<0,0001$; Heritage: $\mathrm{F}=33,6489$ e $\mathrm{p}<0,0001$; Willamette: $\mathrm{F}=12,1548$ e $\mathrm{p}=0,0028$; Golden Bliss: $F=42,4856$ e $p<0,0001$; Fallgold: $F$ $=149,1154$ e $\mathrm{p}<0,0001$; Schönemann: $\mathrm{F}=31,6966 \mathrm{e}$ $p<0,0001$; e, Bababerry: $F=246,7600$ e $p<0,0001$ ), exceto para Polana, que teve comportamento linear ( $\mathrm{F}$ $=18,2186$ e $p=0,0016$ ). Para as cultivares Summer, Heritage e Willamette ocorreram decréscimos nos 
percentuais de sobrevivência da dose 2 para $4 \mathrm{~g} \mathrm{~L}^{-1}$ de carvão ativado e isso representou 23,3, 7,7 e 25,9\%, respectivamente (Figura 1B). Já, para as demais cultivares, ao comparar a dose 2 com $4 \mathrm{~g} \mathrm{~L}^{-1}$ de carvão ativado, foram verificados acréscimos que variaram de $2,3 \%$ para cultivar Schönemann à $247,6 \%$ na 'Fallgold'.

A eficiente sobrevivência das cultivares Indian Summer, Heritage e Willamette na dose de $2 \mathrm{~g} \mathrm{~L}^{-1}$, pode ter ocorrido, em função de uma melhor adaptação das cultivares a menores concentrações de carvão ativado. ALBINO et al. (2010), estudando a cultura do Bacupari (Rheedia brasiliensis Mart.), afirmam que para algumas espécies ou até mesmo cultivares, é conveniente o uso de antioxidantes em menores concentrações $\left(1 \mathrm{~g} \mathrm{~L}^{-1}\right)$, evitando dessa forma, alguns efeitos indesejados que o acúmulo de carvão ativado pode proporcionar ao meio de cultura.

Para a variável dependente, percentual de estabelecimento não ocorreu significância para o efeito de cultivar $(\mathrm{F}=0,20 ; \mathrm{p}=0,9843)$, dose $(\mathrm{F}=$ $0,47 ; p=0,6279)$ e nem para a interação entre os fatores de tratamento testados $(\mathrm{F}=0,92 \mathrm{e} \mathrm{p}=0,5451)$.
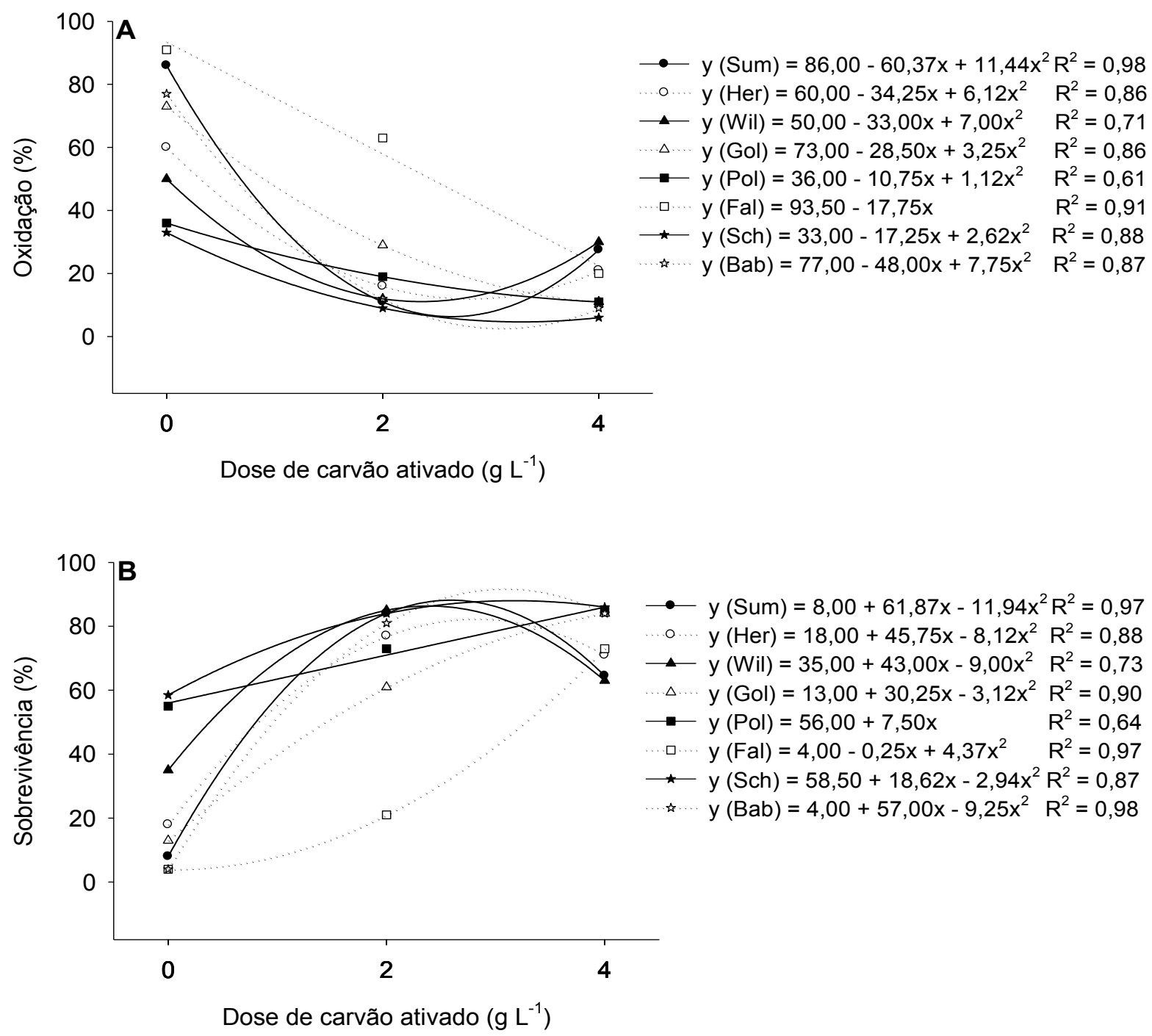

Figura 1. Percentual de oxidação (A), sobrevivência (B) de explantes das cultivares de framboeseira (Indian Summer (Sum), Heritage (Her), Willamette (Wil), Golden Bliss (Gol), Polana (Pol), Fallgold (Fal), Schönemann (Sch) e Bababerry (Bab)), em função de doses de carvão ativado. UFPel, Pelotas, RS, 2013/14.

Figure 1. Percentage of oxidation (A), survival (B) from explants of the Indian summer (Sum), Heritage (Her), Willamette (Wil), Golden Bliss (Gol), Polana (Pol), Fallgold (Fal), Schönemann (Sch) and Bababerry, as a function of activated carbon doses. UFPel, Pelotas, RS, 2013/14. 
Tabela 3. Coeficientes de correlação de Pearson e valores de $p$ entre as variáveis dependentes. UFPel, Pelotas, RS, 2014/15.

Table 3. Pearson correlation coefficients and p values among dependent variables. UFPel, Pelotas, RS, 2014/15.

\begin{tabular}{cccccc}
\hline Variáveis & $\begin{array}{c}\text { Oxidação } \\
(1)\end{array}$ & $\begin{array}{c}\text { Sobrevivência } \\
(2)\end{array}$ & $\begin{array}{c}\text { Estabelecimento } \\
(3)\end{array}$ & $\begin{array}{c}\text { Contaminação } \\
\text { fúngica } \\
(4)\end{array}$ & $\begin{array}{c}\text { Contaminação } \\
\text { bacteriana } \\
(5)\end{array}$ \\
\hline \multirow{2}{*}{$(1)$} & \multirow{2}{*}{1,000} & $-0,967^{*}$ & $-0,147$ & 0,231 & 0,280 \\
& & $<0,0001^{* *}$ & 0,153 & 0,024 & 0,006 \\
$(2)$ & & 1,000 & 0,011 & $-0,4256$ & $-0,430$ \\
$(3)$ & & 0,918 & $<0,0001$ & $<0,0001$ \\
$(4)$ & & 1,000 & 0,060 & $-0,008$ \\
$(5)$ & & & 0,558 & 0,939 \\
& & & & 1,000 & 0,472 \\
& & & & & $<0,0001$ \\
\hline
\end{tabular}

* Coeficiente de correlação de Pearson. ** Valores de $p$.

Para os percentuais de perdas de explantes obtidos com contaminações fúngicas (Tabela 2), verificou-se que no controle $\left(0 \mathrm{~g} \mathrm{~L}^{-1}\right)$ a cultivar Heritage foi a que obteve maiores perdas por contaminações fúngicas. Para as demais doses de carvão ativado, não houveram diferenças estatísticas entre as cultivares.

Quanto a perda por contaminações bacterianas, para a dose de $2 \mathrm{~g} \mathrm{~L}^{-1}$, constatou-se que a cultivar Fallgold, destacou-se em relação as demais. Para a dose de $4 \mathrm{~g} \mathrm{~L}^{-1}$, as maiores perdas bacterianas ocorreram na cultivar Indian Summer.

Em relação às correlações entre as variáveis dependentes avaliadas nos explantes das cultivares de framboeseiras submetidos a doses de carvão ativado (Tabela 3 ), os percentuais de oxidação e sobrevivência $(r=-0,97 ; p<0,0001)$ evidenciaram elevado coeficiente de correlação negativo. Fato que representa quando ocorre aumento no percentual de oxidação, igualmente é verificado redução no percentual de sobrevivência. Coeficientes de correlação negativos, porém, mais baixos, foram verificados entre sobrevivência e contaminação fúngica $(\mathrm{r}=-0,43 ; \mathrm{p}<0,0001)$ e bacteriana $(\mathrm{r}=$ $0,43 ; \mathrm{p}<0,0001)$, o que demonstra que quanto maior a presença de contaminações fúngicas e bacterianas, menor foi o percentual de sobrevivência.

Considerando cada cultivar individualizada, em todas as cultivares ocorreram aumentos nos percentuais de oxidação e consequentemente, reduções nos percentuais de sobrevivência (Indian Summer $(r=-0,99 ; p<0,0001)$, Heritage $(r=-0,98$; $\mathrm{p}<0,0001)$, Willamette $(\mathrm{r}=-0,98 ; \mathrm{p}<0,0001)$,
Golden Bliss $(\mathrm{r}=-0,98 ; \mathrm{p}<0,0001)$, Polana $(\mathrm{r}=-0,98 ; \mathrm{p}<0,0001)$, Fallgold $(\mathrm{r}=-0,96$; $\mathrm{p}<0,0001)$, Schönemann $(\mathrm{r}=-0,86 ; \mathrm{p}=0,0003)$, e Bababerry $(\mathrm{r}=-0,94 ; \mathrm{p}<0,0001))$. Também, verificaram-se decréscimos na sobrevivência em função de aumentos nos percentuais de contaminação fúngica nas cultivares Heritage $(r=-0,92 ; p<0,0001)$, Willamette $(\mathrm{r}=-0,68 ; \mathrm{p}=0,01)$, e Schönemann $(\mathrm{r}=-0,65 ; \mathrm{p}=0,02) ; \mathrm{e}$, nos percentuais de contaminação bacteriana para as cultivares Willamette $(r=-0,76$; $\mathrm{p}=0,004)$ e Golden Bliss $(\mathrm{r}=-0,68 ; \mathrm{p}=0,01)$.

Somente ocorreu aumento no percentual de contaminação fúngica e posterior acréscimo na contaminação bacteriana para as cultivares Fallgold $(r=0,76 ; p=0,004) e$, Bababerry $(r=0,84 ; p=0,0007)$. Da mesma forma, o aumento da oxidação resultou em aumentos nos percentuais de contaminação fúngica nas cultivares Heritage $(r=0,87 ; \mathrm{p}=0,0003)$ e Willamette $(r=0,59 ; \mathrm{p}=0,04)$ e aumentos na contaminação bacteriana na cultivar Willamette $(\mathrm{r}=0,76 ; \mathrm{p}=0,004)$.

\section{CONCLUSÃO}

A dose de $4 \mathrm{~g} \mathrm{~L}^{-1}$ de carvão ativado, foi eficiente na redução da oxidação in vitro para as cultivares Golden Bliss, Polana, Fallgold, Schönemann e Bababerry.

Para as cultivares Indian Summer, Heritage e Willamette a dose $2 \mathrm{~g} \mathrm{~L}^{-1}$ de carvão ativado é a mais indicada para controlar a oxidação fenólica em explantes. 
A correlação negativa entre oxidação e sobrevivência, evidenciou que o incremento de oxidação entre os explantes, acarreta em redução no percentual de sobrevivência dos mesmos.

\section{REFERÊNCIAS}

AFFONSO LB et al. 2015. Microjardim clonal de mirtileiro em sistemas de cultivo sem solo. Revista Brasileira de Fruticultura 37: 1037-1044.

ALBINO BES et al. 2010. Controle da oxidação no estabelecimento in vitro de bacupari. In: XIX Congresso de Pós-Graduação da UFLA. Anais..... Lavras: Universidade Federal de Lavras. p.225-228.

ANDRADE MW et al. 2000. Micropropagação da aroeira (Myracrodruon urundeuva Fr. All). Ciência e Agrotecnologia 24: 174-180.

ANTONIOLLI LR et al. 2011. Controle alternativo de podridões pós-colheita de framboesas. Pesquisa Agropecuária Brasileira 46: 979-984.

ANTUNES LEC. 2006. Amora-preta (Rubus spp). Revista Brasileira de Fruticultura 28: 339-558.

FACHINELLO JC et al. 2011. Situação e perspectivas da fruticultura de clima temperado no Brasil. Revista Brasileira de Fruticultura 33: 109-120.

GALDIANO-JÚNIOR RF et al. 2010. Morfologia do fruto, semente e propagação in vitro de Caularthron bicornutum (Orchidaceae). Revista EPeQ Fafibe 1: 64-68.

GONÇALVES ED et al. 2011. Implantação, cultivo e pós-colheita de framboesa no Sul de Minas Gerais. Belo Horizonte: EPAMIG. 5p. (Circular Técnica, 145).

GRATTAPAGLIA D \& MACHADO MA. 1998. Micropropagação. In: TORRES AC et al. (Eds.) Cultura de Tecidos e Transformação Genética de Plantas. Brasília: Embrapa. p.183-260.

HAN C et al. 2004. Edible coatings to improve storability and enhance nutritional value of fresh and frozen strawberries (Fragaria X ananassa) and raspberries (Rubus idaeus). Postharvest Biology and Technology 33: 67-78.

JUNGHANS TG \& SOUZA AS. 2013. Aspectos práticos da micropropagação de plantas. 2. ed. Brasília: Embrapa. 407p.

MURASHIGE T \& SKOOG F. 1962. A revised medium for rapid growth and bioassays with tobacco tissue cultures. Physiologia Plantarum 15: 473-497.

PAIVA PD de $\mathrm{O}$ et al. 2007. Controle da oxidação no cultivo in vitro de embriões de estrelícia (Strelitzia reginae). Revista Brasileira de Horticultura Ornamental 13: 107-112. RASEIRAMC do B et al. 2004. Aspectos técnicos da cultura da framboeseira. Pelotas: Embrapa Clima Temperado. 22p. (Documentos, 120).

SCHUCH MW \& PEIL RMN. 2012. Soilless cultivation systems: A new approach in fruit plants propagation in the south of Brazil. In: International Symposium on Advanced Technologies and management towards sustainable greenhouse ecosystems-Green Syszoll. Acta Horticulturae 952: 877-883.

TEZOTTO-ULIANA JV \& KLUGE RA. 2013. Framboesa: cultura alternativa para pequenas propriedades rurais em regiões subtropicais. Piracicaba: ESALQ. 3p. (Série Produtor Rural, 55).

THOMAS TD. 2008. The role of activated charcoal in plant tissue culture. Biotechnology Advances 26: 618-631. 